\title{
Selective cyclooxygenase-2 inhibitor use and progression of renal function in patients with chronic kidney disease: a single-center retrospective cohort study
}

\author{
This article was published in the following Dove Press journal: \\ International Journal of Nephrology and Renovascular Disease \\ 7 November 2016 \\ Number of times this article has been viewed
}

\author{
Wisit Kaewput ${ }^{1,2}$ \\ Preedee Disorn ${ }^{2}$ \\ Bancha Satirapoj ${ }^{2}$ \\ 'Department of Military \\ and Community Medicine, \\ Phramongkutklao College of \\ Medicine, ${ }^{2}$ Department of Medicine, \\ Phramongkutklao Hospital and \\ College of Medicine, Bangkok, \\ Thailand
}

\begin{abstract}
Background: The use of selective COX-2 (sCOX-2) inhibitors with acute kidney injury, salt water retention, and cardiovascular events have been correlated in subjects with normal kidney function, but sCOX-2 inhibitor use concerning the progression of chronic kidney disease (CKD) remains uncertain.
\end{abstract}

Objectives: To determine the progression of renal function and electrolyte abnormalities among CKD patients after using sCOX-2 inhibitors during short- and long-term periods.

Methods: The study employed a retrospective cohort design comprising all types of CKD patients with and without sCOX-2 inhibitors (celecoxib and etoricoxib). Data collected included medical data, estimated glomerular filtration rate (eGFR), and serum electrolytes at 3 and 6 months between January 2009 and January 2014. Subjects attended the outpatient clinic and were then followed up until discontinuation of the drugs at years 1 and 2 until May 2016.

Results: Ninety-two CKD patients on SCOX-2 inhibitors and 92 CKD patients without SCOX-2 inhibitors were included. The sCOX-2 inhibitor group showed more decline in eGFR than the control group at 3 and 6 months of follow-up $\left(-8.27 \pm 9.75 \mathrm{vs}-1.64 \pm 6.05 \mathrm{~mL} / \mathrm{min} / 1.73 \mathrm{~m}^{2}\right.$, $P<0.001$ and $-12.36 \pm 6.48$ vs $-4.31 \pm 5.11 \mathrm{~mL} / \mathrm{min} / 1.73 \mathrm{~m}^{2}, P=0.001$, respectively) and at 1 and 2 years of follow-up after subjects discontinued sCOX-2 $(-6.84 \pm 10.34 \mathrm{vs}-1.61 \pm 8.93 \mathrm{~mL} /$ $\mathrm{min} / 1.73 \mathrm{~m}^{2}, P=0.004$ and $-10.26 \pm 10.19 \mathrm{vs}-5.12 \pm 8.61 \mathrm{~mL} / \mathrm{min} / 1.73 \mathrm{~m}^{2}, P=0.005$, respectively). In addition, the sCOX-2 inhibitor group had significantly more increased serum potassium during the study follow-up than the control group.

Conclusion: The sCOX-2 inhibitors are associated with an increased risk for rapid eGFR decline and hyperkalemia in both the short term and in the long term after sCOX-2 inhibitors were terminated in the setting of a community-based CKD population. For CKD patients, these results suggest that $\mathrm{SCOX}-2$ inhibitors should be closely monitored and chronic exposure to any sCOX-2 inhibitors should be avoided.

Keywords: selective cyclooxygenase-2 inhibitor, long-term renal progression, chronic kidney disease

\section{Introduction}

Nonsteroidal anti-inflammatory drugs (NSAIDs), both nonselective and selective cyclooxygenase (sCOX)-2 inhibitors, are used worldwide. sCOX-2 inhibitors act by inhibiting type 2 cyclooxygenase (COX), which transforms arachidonic acid into prostaglandins. sCOX-2 inhibitors also have a major role in inhibiting tissue inflammation and pain mechanisms. It preserves the gut lining, providing epithelial integrity and maintaining
Correspondence: Wisit Kaewput Department of Military and Community Medicine, Phramongkutklao College of Medicine, 315 Ratwithi Road, Ratchathewi, Bangkok 10400, Thailand Email wisit_nephro@hotmail.com 
platelet function. Many studies have found reduced digestive tract complications, such as incidence of gastric ulcers and gastrointestinal bleeding, using sCOX-2 inhibitors compared with other NSAIDs. However, many reports ${ }^{1-3}$ describe the adverse effects from sCOX-2 inhibitors such as acute kidney injury, glomerular disease, tubulointerstitial disease, fluid electrolytes imbalance, and cardiovascular events in patients with normal renal function. However, short- and long-term effects of sCOX-2 inhibitors in the progression of chronic kidney disease (CKD) remain unclear. ${ }^{4}$ The results from the large cohort study by Kuo et $\mathrm{al}^{5}$ and Gooch et $\mathrm{al}^{6}$ showed that the sCOX-2 inhibitors might increase the risk of end-stage renal disease, which was in contrast with the result from the systematic review in the following years that concluded no definite renal outcome in a long-term period. The current study was conducted to mainly determine the relationship between sCOX-2 inhibitors and renal progression among CKD patients in short- and long-term periods. ${ }^{4}$

\section{Materials and methods Study design and population}

A retrospective cohort design was used, and the subjects consisted of all adult patients (aged $\geq 18$ years, $n=184$ ) with a diagnosis of CKD as designated by Kidney Disease Improving Global Outcomes criteria, ${ }^{7}$ who were seen for any care at the Outpatient Medicine Clinic, Phramongkutklao Hospital, Bangkok, Thailand, between January 1, 2009 and January 1, 2014. After we determined the patients' baseline characteristics and collected early renal outcomes data, all participants discontinued NSAIDs and were closely followed up until May 1, 2016 to assess the long-term outcome. The study was approved by the Institutional Review Boards of the Phramongkutklao Hospital and College of Medicine. The CKD patients were randomly assigned to participate in each study group. All participants received standard treatment for CKD within 3 months before starting the study. The control group was defined as CKD patients who did not receive any NSAIDs during the study period. The other group was made up of CKD patients who received sCOX-2 inhibitors such as celecoxib and etoricoxib for more than 3 months. Exclusion criteria included patients with CKD Stage 5, CKD caused due to obstructive uropathy, and use of other NSAIDs or nephrotoxic agents during the study period. Complete medical history and physical examination were performed on all subjects.

\section{Laboratory investigation}

Comprehensive serum chemistries such as creatinine, electrolytes, albumin, cholesterol, triglycerides, and hemoglobin level were measured at baseline. Serum creatinine and potassium were also continually assessed during the study at months 3 and 6 and after NSAIDs termination at years 1 and 2. Estimated glomerular filtration rate (eGFR) was estimated using the Chronic Kidney Disease Epidemiology Collaboration equation (CKD-EPI) formula.

\section{Statistical analysis}

The estimated sample size was calculated, and 92 patients per study arm were sufficient to detect the difference of eGFR using a two-sided $\alpha$ of 0.05 and $80 \%$ power between study groups. Data are presented as mean, standard deviation for continuous variables or as a percentage for categorical variables. Normal data distribution was confirmed using the Kolmogorov-Smirnov test. Data were analyzed using $\chi^{2}$ tests or Fisher's exact tests for categorical variables and the independent $t$-test for continuous variables. All statistical analyses were performed using the SPSS version 22.0 (IBM Corporation, Armonk, NY, USA) for Windows, and the level of statistical significance was set as $P<0.05$.

The Phramongkutklao Army Hospital Institutional Review board approved the study. All patients provided written informed consent to participate in the study.

\section{Results}

\section{Characteristics of subjects}

A total of 184 patients diagnosed with CKD at the Outpatient Medicine Clinic, Bangkok, were enrolled in the study. Ninety-two patients were assigned to the control group, and 92 individuals to the sCOX-2 group. The indications for specific COX-2 inhibitor administration in the sCOX-2 inhibitor group were presence of chronic myofascial pain syndrome $(n=24[26.09 \%])$ and chronic bone and joints diseases such as spondylogenic back pain, degenerative scoliosis, osteoarthritis, etc. $(n=68[73.91 \%])$. The mean daily dose of celecoxib and etoricoxib was $227.59 \pm 72.28 \mathrm{mg} / \mathrm{d}$ and $85.91 \pm 10.16 \mathrm{mg} / \mathrm{d}$, respectively. The mean exposure duration of celecoxib and etoricoxib was 98.49 \pm 26.56 days and 101.54 \pm 30.48 days, respectively. Characteristics of the study population are shown in Table 1. No significant differences were found regarding age, sex, cause of CKD, eGFR, and sodium and potassium levels.

\section{Metabolic outcomes during the study period}

During the whole study period, patients did not alter their usual medical treatment, such as using antihypertensive and hypolipidemic agents. No significant change in body weight and blood pressures was observed between the patients with or without sCOX-2 inhibitors (data shown in Table 2). 
Table I Baseline characteristics of study participants

\begin{tabular}{|c|c|c|c|}
\hline Characteristic & $\begin{array}{l}\text { Selective COX-2 } \\
\text { group }(n=92)\end{array}$ & $\begin{array}{l}\text { Control group } \\
(n=92)\end{array}$ & $P$-value \\
\hline Age (years) & $71.16 \pm 11.14$ & $72.12 \pm 9.60$ & 0.533 \\
\hline Sex (male), n (\%) & $59(64)$ & $66(7 I)$ & 0.268 \\
\hline \multicolumn{4}{|l|}{$\begin{array}{l}\text { Underlying disease, } \\
\mathrm{n}(\%)\end{array}$} \\
\hline Diabetes mellitus & $26(28)$ & $37(40)$ & 0.087 \\
\hline Hypertension & $73(79)$ & $89(97)$ & $<0.001$ \\
\hline Dyslipidemia & $49(53)$ & $75(8 \mathrm{I})$ & $<0.001$ \\
\hline $\begin{array}{l}\text { Coronary artery } \\
\text { disease }\end{array}$ & $4(4)$ & $3(3)$ & 0.699 \\
\hline Stroke & $4(4)$ & $2(2)$ & 0.402 \\
\hline Cause of CKD, $n(\%)$ & & & 0.517 \\
\hline $\begin{array}{l}\text { Chronic } \\
\text { glomerulonephritis }\end{array}$ & $4(4.3)$ & $\mathrm{I}(\mathrm{I} . \mathrm{I})$ & \\
\hline $\begin{array}{l}\text { Diabetic } \\
\text { nephropathy }\end{array}$ & $21(22.8)$ & $25(27.2)$ & \\
\hline Nephrosclerosis & $38(4 \mid .3)$ & $34(37)$ & \\
\hline Others & $29(31.5)$ & $32(34.8)$ & \\
\hline ACEI/ARB, $n(\%)$ & $53(57.6)$ & 45 (48.9) & 0.237 \\
\hline Statin, n (\%) & $64(69.6)$ & $73(79.3)$ & 0.128 \\
\hline \multicolumn{4}{|l|}{ Biochemical profiles } \\
\hline Hemoglobin (g/dL) & $12.56 \pm 1.82$ & $12.53 \pm 1.62$ & 0.891 \\
\hline Cholesterol (mg/dL) & $|76.97 \pm 36.5|$ & $168.63 \pm 40.09$ & 0.142 \\
\hline Triglyceride (mg/dL) & $130.23 \pm 40.26$ & $124.63 \pm 51.73$ & 0.413 \\
\hline Albumin (g/L) & $4.15 \pm 0.42$ & $4.18 \pm 0.32$ & $0.54 I$ \\
\hline $\begin{array}{l}\text { eGFR } \\
\left(\mathrm{mL} / \mathrm{min} / 1.73 \mathrm{~m}^{2}\right)\end{array}$ & $41.23 \pm 12.21$ & $39.5 I \pm 9.67$ & 0.291 \\
\hline $\begin{array}{l}\text { Serum sodium } \\
(\mathrm{mEq} / \mathrm{L})\end{array}$ & $138.56 \pm 3.23$ & $139.29 \pm 2.99$ & 0.114 \\
\hline $\begin{array}{l}\text { Serum potassium } \\
(\mathrm{mEq} / \mathrm{L})\end{array}$ & $4.22 \pm 0.49$ & $4.34 \pm 0.38$ & 0.079 \\
\hline
\end{tabular}

Notes: Data presented as number and percentage or mean and SD; analysis carried out by $\chi^{2}$ or Fisher's exact tests for categorical variables and independent $t$-test for continuous variables.

Abbreviations: COX, cyclooxygenase; CKD, chronic kidney disease, eGFR, estimated glomerular filtration rate; ACEI/ARB, angiotensin-converting enzyme inhibitor/angiotensin II receptor blockers; SD, standard deviation.

Table 2 Changes from baseline vital signs parameters

\begin{tabular}{|c|c|c|c|}
\hline Parameters & $\begin{array}{l}\text { Selective COX-2 } \\
\text { group }(n=92)\end{array}$ & $\begin{array}{l}\text { Control group } \\
(n=92)\end{array}$ & $P$-value \\
\hline Baseline SBP $(\mathrm{mmHg})$ & $|34.57 \pm| 4.3 \mid$ & $|32.60 \pm| \mid .72$ & 0.303 \\
\hline $\begin{array}{l}\text { Change at the } \\
\text { end point }(\mathrm{mmHg})\end{array}$ & $\mathrm{I} .5 \mathrm{I} \pm 8.89$ & $-0.47 \pm 7.11$ & 0.096 \\
\hline Baseline DBP (mmHg) & $75.84 \pm 11.43$ & $72.79 \pm 10.13$ & 0.057 \\
\hline $\begin{array}{l}\text { Change at the } \\
\text { end point }(\mathrm{mmHg})\end{array}$ & $0.39 \pm 8.92$ & $0.33 \pm 8.44$ & 0.966 \\
\hline Baseline BW (kg) & $65.15 \pm 12.47$ & $66.91 \pm 11.29$ & 0.318 \\
\hline $\begin{array}{l}\text { Change at the } \\
\text { end point }(\mathrm{mmHg})\end{array}$ & $0.01 \pm 1.24$ & $0.8 \mathrm{I} \pm 0.97$ & 0.653 \\
\hline
\end{tabular}

Notes: Data are mean and SD. Year 2 values compared with baseline by using independent $t$-test for continuous variables: $P<0.05$.

Abbreviations: COX-2, cyclooxygenase-2; SD, standard deviation; SBP, systolic blood pressure; DBP, diastolic blood pressure; BW, body weight.
Routine blood chemistry and hematologic parameters such as albumin, cholesterol, triglycerides, and hemoglobin did not significantly differ in both groups.

\section{Renal outcomes during the study period}

eGFRs calculated using the CKD-EPI formula during the study are shown in Table 3; no significant differences were observed in eGFR between the two groups (41.23 \pm 1.27 and $\left.39.51 \pm 1.01 \mathrm{~mL} / \mathrm{min} / 1.73 \mathrm{~m}^{2} ; P=0.291\right)$. eGFR decreased significantly in the sCOX-2 group when compared with the control group after drug use for months $3(32.96 \pm 10.89$ and $\left.37.87 \pm 11.03 \mathrm{~mL} / \mathrm{min} / 1.73 \mathrm{~m}^{2} ; P=0.003\right)$ and $6(25.79 \pm 6.51$ and $\left.35.06 \pm 10.39 \mathrm{~mL} / \mathrm{min} / 1.73 \mathrm{~m}^{2} ; P<0.001\right)$. Furthermore, no significant change was observed between the two groups at years 1 and 2 after drugs were withdrawn. However, the decrease in eGFR significantly differed in both groups during the whole study period (data shown in Table 4). The number and percentage of patients receiving celecoxib and etoricoxib, total dose, duration of exposure, and mean daily dose are shown in Table 5. The semiquantitative urine protein

Table 3 eGFR during the study period

\begin{tabular}{llll}
\hline $\begin{array}{l}\text { eGFR } \\
\left(\mathbf{m L} / \mathbf{m i n} / 1.73 \mathbf{~ m}^{2}\right)\end{array}$ & $\begin{array}{l}\text { Selective } \\
\text { COX-2 group }\end{array}$ & $\begin{array}{l}\text { Control } \\
\text { group }\end{array}$ & P-value \\
\hline $\begin{array}{l}\text { During drug usage } \\
\quad \text { Baseline }\end{array}$ & $41.23 \pm 1.27$ & $39.51 \pm 1.01$ & 0.291 \\
$\quad$ Month 3 & $32.96 \pm 10.89$ & $37.87 \pm 11.03$ & 0.003 \\
$\quad$ Month 6 & $25.79 \pm 6.51$ & $35.06 \pm 10.39$ & $<0.001$ \\
After drug withdrawn & & & \\
$\quad$ Year I & $35.04 \pm 11.42$ & $38.37 \pm 13.79$ & 0.138 \\
Year 2 & $31.91 \pm 12.30$ & $34.87 \pm 13.07$ & 0.206 \\
\hline
\end{tabular}

Notes: Data are mean and SD. Comparison between selective COX-2 NSAIDs group and control group with analysis using independent $t$-test for continuous variables: $P<0.05$.

Abbreviations: eGFR, estimated glomerular filtration rate; COX-2, cyclooxygenase-2; SD, standard deviation; NSAIDs, nonsteroidal anti-inflammatory drugs.

Table 4 Changes from baseline eGFR

\begin{tabular}{llll}
\hline $\begin{array}{l}\text { Mean difference eGFR } \\
\left(\mathbf{m L} / \mathbf{m i n} / 1.73 \mathbf{~ m}^{2}\right)\end{array}$ & $\begin{array}{l}\text { Selective } \\
\text { COX-2 group }\end{array}$ & $\begin{array}{l}\text { Control } \\
\text { group }\end{array}$ & P-value \\
\hline During drug usage & & & \\
$\quad$ Months 0-3 & $-8.26 \pm 9.75$ & $-1.64 \pm 6.05$ & $<0.001$ \\
$\quad$ Months 0-6 & $-12.36 \pm 6.48$ & $-4.32 \pm 5.10$ & 0.001 \\
After drug withdrawn & & & \\
$\quad$ Years 0-I & $-6.83 \pm 10.34$ & $-1.61 \pm 8.93$ & 0.004 \\
$\quad$ Years 0-2 & $-10.26 \pm 10.19$ & $-5.12 \pm 8.61$ & 0.005 \\
\hline
\end{tabular}

Notes: Data are mean difference and SD. Comparison between selective COX-2 NSAIDs group and control group with independent $t$-test for continuous variables: $P<0.05$.

Abbreviations: eGFR, estimated glomerular filtration rate; COX-2, cyclooxygenase-2; SD, standard deviation; NSAIDs, nonsteroidal anti-inflammatory drugs. 
Table 5 Quantification of daily use for selective COX-2 inhibitors

\begin{tabular}{lll}
\hline Quantification & $\begin{array}{l}\text { Celecoxib, } \mathbf{N}=\mathbf{5 3} \\
\mathbf{( 5 7 . 6 1 \% )}\end{array}$ & $\begin{array}{l}\text { Etoricoxib, N=39 } \\
\mathbf{( 4 2 . 3 9 \% )}\end{array}$ \\
\hline Total dose (mg) & $22,415.09 \pm 7,818.70$ & $\mathbf{8 , 7 2 3 . 0 8 \pm 2 , 7 3 2 . 5 9}$ \\
Exposure duration (days) & $98.49 \pm 26.56$ & $101.54 \pm 30.48$ \\
Mean dose per day (mg) & $227.59 \pm 72.28$ & $85.91 \pm 10.16$
\end{tabular}

Abbreviation: COX-2, cyclooxygenase-2.

Table 6 Urine protein during study period ${ }^{a}$

\begin{tabular}{|c|c|c|c|}
\hline $\begin{array}{l}\text { Urine protein } \\
\text { (semiquantitative } \\
\text { method) }\end{array}$ & $\begin{array}{l}\text { Selective } \\
\text { COX-2 group } \\
(\mathrm{n}=92)\end{array}$ & $\begin{array}{l}\text { Control group } \\
(n=92)\end{array}$ & $\begin{array}{l}P \text {-value } \\
\text { between } \\
\text { group } \\
\end{array}$ \\
\hline Baseline, n (\%) & & & 0.245 \\
\hline Negative & $64(69.6)$ & $65(70.7)$ & \\
\hline Trace & II (I2) & $6(6.5)$ & \\
\hline I+ & $14(15.2)$ & $14(15.2)$ & \\
\hline $2+$ & $2(2.2)$ & $7(7.6)$ & \\
\hline $3+$ & I (I.I) & 0 & \\
\hline Months 3-6, n (\%) & & & 0.604 \\
\hline Negative & $53(57.6)$ & $46(50)$ & \\
\hline Trace & $16(17.4)$ & $15(16.3)$ & \\
\hline I+ & $16(17.4)$ & $23(25)$ & \\
\hline $2+$ & $7(7.6)$ & $8(8.7)$ & \\
\hline Years I-2, n (\%) & & & 0.354 \\
\hline Negative & $63(68.5)$ & $54(58.7)$ & \\
\hline Trace & $8(8.7)$ & $10(10.9)$ & \\
\hline $\mathrm{I}+$ & $18(19.6)$ & $22(23.9)$ & \\
\hline $2+$ & $2(2.2)$ & $6(6.5)$ & \\
\hline $3+$ & 0 & 0 & \\
\hline $4+$ & I (I.I) & 0 & \\
\hline $\begin{array}{l}P \text {-value between } \\
\text { different time }\end{array}$ & 0.213 & 0.124 & \\
\hline
\end{tabular}

Notes: Data presented as number and percentage; analysis using $\chi^{2}$ or Fisher's exact tests for categorical variables: $P<0.05$. ${ }^{a}$ Cellular casts and sterile pyuria were not found during study period.

Abbreviation: COX-2, cyclooxygenase-2.

Table 7 Changes from baseline serum sodium and potassium levels

\begin{tabular}{llll}
\hline $\begin{array}{l}\text { Mean difference } \\
(\mathbf{m E q} / \mathrm{L})\end{array}$ & $\begin{array}{l}\text { Selective } \\
\text { COX-2 group }\end{array}$ & $\begin{array}{l}\text { Control } \\
\text { group }\end{array}$ & P-value \\
\hline $\begin{array}{l}\text { Serum sodium } \\
\quad \text { Months 0-3 }\end{array}$ & $0.86 \pm 3.14$ & $0.63 \pm 3.32$ & 0.616 \\
$\begin{array}{l}\text { Serum potassium } \\
\text { During drug usage }\end{array}$ & & & \\
$\quad$ Months 0-3 & $0.23 \pm 0.44$ & $0.09 \pm 0.47$ & 0.038 \\
$\quad$ Months 0-6 & $0.25 \pm 0.45$ & $0.05 \pm 0.47$ & 0.003 \\
Serum potassium & & & \\
After drug withdrawn & & & \\
$\quad$ Years 0-I & $0.11 \pm 0.45$ & $-0.12 \pm 0.52$ & 0.001 \\
$\quad$ Years 0-2 & $0.11 \pm 0.47$ & $-0.03 \pm 0.47$ & 0.031 \\
\hline
\end{tabular}

Notes: Data are mean difference and SD. Comparison between selective COX2 NSAIDs group and control group with analysis using independent $t$-test for continuous variables: $P<0.05$.

Abbreviations: COX-2, cyclooxygenase-2; SD, standard deviation; NSAIDs, nonsteroidal anti-inflammatory drugs. examination (Table 6) did not significantly differ in both groups and at different time sequences. Moreover, the cellular casts and sterile pyuria were not reported in the urinary examination during the study period.

\section{Serum sodium and potassium levels change during sCOX-2 use}

Serum sodium and potassium levels during drug use are shown in Table 7. No significant differences were observed in serum sodium levels between the two groups. In contrast, serum potassium levels increased significantly in the sCOX-2 group during the study period.

\section{Safety profile}

During the 2-year study period, no serious adverse events were reported related to sCOX-2 NSAIDs use, such as acute renal failure, dialysis, kidney transplantation, and cardiovascular event.

\section{Discussion}

The present study constitutes the first retrospective cohort study of sCOX-2 NSAIDs and renal progression in a community-based CKD population. The eGFR decreased significantly in the sCOX-2 group when compared with the control group during drug use. In contrast, the serum potassium level increased significantly in the sCOX-2 group during the same period. Regarding long-term renal outcome, the eGFRs were improved after discontinuing NSAIDs, but they did not return to normal baseline. Although withdrawing sCOX-2 inhibitors improved renal function in years 1 and 2 , mean difference in eGFR in the sCOX-2 group showed a greater decline than in the control group long term. These findings suggest that some permanent kidney damage combined with worsening renal hemodynamic effects might have occurred after using sCOX- 2 inhibitors since the early period.

The previous animal models ${ }^{8}$ demonstrated that renal prostaglandins synthesized mainly by COX-1 and COX-2 served as compensatory mechanisms of renal hemodynamics. Therefore, nonselective NSAIDs and sCOX-2 NSAIDs will also theoretically regulate and reduce renal prostaglandin formation by inhibiting COX, thereby worsening renal hemodynamics. COX-2 can be found in thick ascending limbs, macula densa, glomeruli, and afferent and efferent arterioles. A subsequent clinical study has also provided evidence that COX-2 inhibitors affect renal hemodynamics. ${ }^{9}$

Acute kidney injury caused by sCOX-2 inhibitors was encountered several days after starting drug use. The previous case report in 2002 clearly demonstrated that sCOX-2 
inhibitors caused acute tubulointerstitial nephritis (ATIN). ${ }^{2}$ Moreover, other studies ${ }^{9}$ have revealed that $\mathrm{sCOX}-2$ inhibitors also caused acute ischemic tubular necrosis, nephrotic syndrome due to minimal change disease, acute papillary necrosis, ${ }^{1,10}$ hyperkalemia, and type 4 renal tubular acidosis.

The previous study showed that conventional NSAIDs increased the risk of renal progression and end-stage renal disease in CKD. The large cohort studies from Gooch et al, ${ }^{6}$ Hemmelgarn et al, ${ }^{11}$ and Yarger et $\mathrm{al}^{12}$ demonstrated that accelerated CKD progression occurred in $10.9 \%-13.3 \%$ of the study participants. Although high cumulative NSAID exposure was significantly associated with an increased risk of accelerated CKD progression, regular NSAID use was not associated with an increased risk of accelerated CKD progression, especially among Stage 3 CKD patients. According to Kuo et al, ${ }^{5} \mathrm{CKD}$ patients using NSAIDs had an increased risk for ESRD. In contrast, Evans et $\mathrm{al}^{13}$ reported no significant association between aspirin use and renal function decline.

The recent meta-analysis confirmed that sCOX-2 inhibitors such as celecoxib, rofecoxib, parecoxib, etoricoxib, and lumiracoxib had class effects, causing abnormal renal function and diseases. ${ }^{3,14,15}$ The risk factors comprised receiving high dose, prolonged drug use more than 6 months, and comorbid diseases.

The result of the present study also demonstrated that CKD patients receiving sCOX-2 inhibitors had partially improved renal function following discontinuation of NSAIDs at years 1 and 2. It was hypothesized that prolonged use of sCOX-2 NSAIDs might produce renal fibrosis by prolonging subclinical renal ischemia or the healing process from subclinical interstitial nephritis after delayed termination of causative drugs. The present study also demonstrated data analysis of the semiquantitative urine protein examination (Table 6). The data suggest that most patients have a urine indicative of renal tubulointerstitial disease pattern such as minimal proteinuria (urine protein $<2+$ ) and no cellular casts. Previous reports have clearly established a causative relationship between sCOX-2 inhibitors and tubulointerstitial disease such as acute tubular necrosis and ATIN. ${ }^{16}$

The etiology of ATIN most likely to be encountered is that of idiosyncratic drugs, not dependent on dosage and duration of drug exposure. Early discontinuation of causative drugs was the treatment of choice. A good prognosis was associated with rapid termination of drug use, especially within 7 days. ${ }^{17,18}$ Delayed drug termination has caused permanent renal fibrosis and affects renal function. Additionally, subgroup analysis found no different renal outcomes between any types, any dosage, and duration between 3 and 6 months in using NSAIDs. Although eGFR at the end of study did not differ between two groups, the rate decline in eGFR over 2 years worsened more than twice in the sCOX-2 inhibitors group than in the control group. These data indicate the possibility that subclinical ATIN might cause deterioration of kidney function in the sCOX-2 inhibitors group. The negative impacts are on patients approaching change in the stage of CKD. ${ }^{7}$ Previous reports have demonstrated that more advanced stage CKD was a factor affecting risks of GFR decline and high mortality in CKD patients. Previous studies supporting this reason, such as those of Nussmeier et $\mathrm{al}^{14}$ and Ejaz et al, ${ }^{19}$ reported that parecoxib and valdecoxib increased the risk of eGFR deterioration and development of CKD by $1.5-2.5$ times. ${ }^{14,19}$ Another study found that sCOX-2 inhibitors caused a $35 \%$ incidence of renal deterioration and abnormal electrolytes side effects in contrast with $16 \%$ in the nonselective COX-2 inhibitors group. ${ }^{20}$ sCOX-2 inhibitor avoidance is imperative to delay renal function deterioration among CKD patients. However, CKD patients requiring sCOX-2 inhibitors use should be closely monitored. Otherwise, hyperkalemia can occur during the early phase when continuing medication and in the long term after sCOX-2 inhibitors termination. These findings were supported by the present data. The possible cause might be from low eGFR and hyporeninemic hypoaldosteronism.

The limitations of this study include: 1) The observational study design - so no kidney biopsy was used to diagnose causative renal diseases, such as acute ischemic tubular necrosis and ATIN; 2) The study did not adjust for the number of participants with underlying hypertension and hyperlipidemia from both groups equally. These were implicated in the deterioration of renal function. However, the participants from both groups controlled blood pressure using angiotensin-converting enzyme inhibitors/angiotensin II receptor blockers and serum lipid levels using statins rather well during the whole study period; 3) The study was done on 184 patients from a tertiary level hospital in Bangkok. It might not be possible to generalize the results. 4) The treated group was a combination of those who received celecoxib and those who received etoricoxib, and so the results might be inconclusive regarding the more nephrotoxic effects because of the limitation of the retrospective cohort design and insufficient power of this study. Celecoxib is unique among its class with many mechanisms of action (such as phosphodiesterase inhibition) other than COX-2 inhibition. ${ }^{21}$

\section{Conclusion}

This study provided evidence that a 3-6 months continuous treatment using sCOX-2 inhibitors effected nearly double the decline in eGFR and increased the risk of hyperkalemia 
in community-based CKD patients, both early on and in the long term. Therefore, it can be implied from these results that sCOX-2 inhibitor avoidance for more than 3 months is imperative to delay renal function deterioration among CKD patients.

\section{Acknowledgments}

This study was supported in part by grants from Phramongkutklao Hospital and the College of Medicine.

\section{Author contributions}

All authors contributed toward data analysis, drafting and critically revising the paper and agree to be accountable for all aspects of the work.

\section{Disclosure}

The authors report no conflicts of interest in this work.

\section{References}

1. Akhund L, Quinet RJ, Ishaq S. Celecoxib-related renal papillary necrosis. Arch Intern Med. 2003;163(1):114-115.

2. Rocha JL, Fernández-Alonso J. Acute tubulointerstitial nephritis associated with the selective COX-2 enzyme inhibitor, rofecoxib. Lancet. 2001;357(9272):1946-1947.

3. Ungprasert P, Cheungpasitporn W, Crowson CS, Matteson EL. Individual non-steroidal anti-inflammatory drugs and risk of acute kidney injury: a systematic review and meta-analysis of observational studies. Eur J Intern Med. 2015;26(4):285-291.

4. Nderitu P, Doos L, Jones PW, Davies SJ, Kadam UT. Non-steroidal anti-inflammatory drugs and chronic kidney disease progression: a systematic review. Fam Pract. 2013;30(3):247-255.

5. Kuo HW, Tsai SS, Tiao MM, Liu YC, Lee IM, Yang CY. Analgesic use and the risk for progression of chronic kidney disease. Pharmacoepidemiol Drug Saf. 2010;19(7):745-751.

6. Gooch K, Culleton BF, Manns BJ, et al. NSAID use and progression of chronic kidney disease. Am J Med. 120(3):280:e1-e7.
7. Levin A, Stevens P, Bilous R, et al; Kidney Disease: Improving Global Outcomes (KDIGO) CKD Work Group. KDIGO 2012 clinical practice guideline for the evaluation and management of chronic kidney disease. Kidney Int Suppl. 2013;3(1):e150.

8. Crofford LJ. COX-1 and COX-2 tissue expression: implications and predictions. J Rheumatol Suppl. 1997;49:15-19.

9. Höcherl K, Endemann D, Kammerl MC, Grobecker HF, Kurtz A. Cyclo-oxygenase-2 inhibition increases blood pressure in rats. $\mathrm{Br} J$ Pharmacol. 2002;136(8):1117-1126.

10. Perazella MA, Tray K. Selective cyclooxygenase-2 inhibitors: a pattern of nephrotoxicity similar to traditional nonsteroidal anti-inflammatory drugs. Am J Med. 2001;111(1):64-67.

11. Hemmelgarn BR, Culleton BF, Ghali WA. Derivation and validation of a clinical index for prediction of rapid progression of kidney dysfunction. QJM. 2007;100(2):87-92.

12. Yarger S, Nwokeji E, Trice S, et al. Puk ${ }_{4}$ Cumulative exposure to nonsteroidal anti-inflammatory drugs (NSAIDS) and the progression of chronic kidney disease (CKD). Value Health. 2011;14(3):A74-A75.

13. Evans M, Fored CM, Bellocco R, et al. Acetaminophen, aspirin and progression of advanced chronic kidney disease. Nephrol Dial Transplant. 2009;24(6):1908-1918.

14. Nussmeier NA, Whelton AA, Brown MT, et al. Complications of the COX-2 inhibitors parecoxib and valdecoxib after cardiac surgery. $N$ Engl J Med. 2005;352(11):1081-1091.

15. Zhang J, Ding EL, Song Y. Adverse effects of cyclooxygenase 2 inhibitors on renal and arrhythmia events: meta-analysis of randomized trials. JAMA. 2006;296(13):1619-1632.

16. Ortiz M, Mon C, Fernández MJ, Sánchez R, Mampaso F, Alvarez Ude F. Tubulointerstitial nephritis associated with treatment with selective Cox-2 inhibitors, celecoxib and rofecoxib. Nefrologia. 2005;25(1):39-43.

17. Gonzalez E, Gutierrez E, Galeano C, et al. Early steroid treatment improves the recovery of renal function in patients with drug-induced acute interstitial nephritis. Kidney Int. 2008;73(8):940-946.

18. Praga M, Gonzalez E. Acute interstitial nephritis. Kidney Int. 2010;77(11):956-961.

19. Ejaz P, Bhojani K, Joshi VR. NSAIDs and kidney. J Assoc Physicians India. 2004;52:632-640.

20. Verrico MM, Weber RJ, McKaveney TP, Ansani NT, Towers AL. Adverse drug events involving COX-2 inhibitors. Ann Pharmacother. 2003;37(9):1203-1213.

21. Fujihara CK, Antunes GR, Mattar AL, et al. Cyclooxygenase-2 (COX-2) inhibition limits abnormal COX-2 expression and progressive injury in the remnant kidney. Kidney Int. 2003;64(6):2172-2181.

\section{Publish your work in this journal}

The International Journal of Nephrology and Renovascular Disease is an international, peer-reviewed open access journal focusing on the pathophysiology of the kidney and vascular supply. Epidemiology, screening, diagnosis, and treatment interventions are covered as well as basic science, biochemical and immunological studies. The manuscript management system is completely online and includes a very quick and fair peer-review system, which is all easy to use. Visit http://www. dovepress.com/testimonials.php to read real quotes from published authors. 